\title{
O conceito de comunidade discursiva e as convergências com a Terminologia
}

\section{The concept of discursive community and its convergences with terminology}

\author{
Márcia Ivo Braz* \\ Severino Carlos da Silva**
}

Resumo: Partindo do conceito de comunidade discursiva, desenvolvido por Swales (1990), incorporado nos estudos voltados para a Terminologia, Lexicografia e linguagens de especialidade, o objetivo deste trabalho é verificar a ocorrência do conceito da referida comunidade e sua influência em investigações de Terminologia. Para tanto, foi realizada uma pesquisa nas bases de dados internacionais Web of Science e Library \& Information Science Abstracts (LISA) e nas bases de dados nacionais $B D T D$ e $B R A P C I$, cujos resultados recuperados foram analisados individualmente. A análise dos artigos revelou que os elementos das comunidades discursivas, apontadas por Swales, correspondem às considerações tecidas pelos autores e são utilizados nos estudos terminológicos aqui relacionados. Nos trabalhos produzidos no Brasil, o autor é bastante relevante, sendo a base direta e indireta nas pesquisas; nos artigos internacionais, os conceitos se aproximam do ponto de vista de Swales, porém esse estudioso não é citado diretamente como referência. Dessa forma, desenvolve-se uma discussão relacionando as características de comunidade discursiva no que tange aos apontamentos encontrados nos artigos, teses e dissertações. Por fim, considera-se que o estudo das teorias conexas aos gêneros textuais e discursivos necessita compor a pauta das investigações voltadas à Terminologia, uma vez que o campo dos dicionários e ferramentas que representam os léxicos especializados são recortes de estruturas profissionais que compartilham consenso e objetivos comuns, assim como formas próprias de comunicação entre os pares (incluindo gêneros e léxico específicos), onde o domínio de conteúdo relevante e a experiência discursiva são fatores de

\footnotetext{
* Professora Assistente da Universidade Federal de Pernambuco. Doutoranda em Ciências da Linguagem (Universidade Católica de Pernambuco). Mestre em Ciência da Informação pela Universidade Federal de Pernambuco. E-mail: marciabraz.ufpe@gmail.com

** Professor Assistente da Universidade de Pernambuco - UPE. Doutorando em Ciências da Linguagem (Universidade Católica de Pernambuco). Mestre em Letras pela Universidade Federal da Paraíba. Especialista em Metodologia do Ensino Superior pela Universidade de Pernambuco. E-mail: carlossilvaprofessor@gmail.com
} 
diferenciação entre os próprios membros, sendo, portanto, as linguagens de especialidade uma das características das comunidades discursivas.

Palavras-chave: Gêneros textuais; Terminologia; Comunidades discursivas.

Abstract: Based on the concept of discursive community, developed by Swales (1990), incorporated in the studies focused on Terminology, Lexicography and specialty languages, the aim of this work is to verify the occurrence of the concept of the referred community and its influence in Terminology investigations. To do so, a search was made in the international databases Web of Science and Library \& Information Science Abstracts (LISA) and in the Brazilian databases BDTD and BRAPCI, whose recovered results were analyzed individually. The analysis of the articles revealed that the elements of the discursive communities, pointed out by Swales, correspond to the considerations made by the authors and are used in the terminological studies related here. In the works produced in Brazil, the author is very relevant, being a direct and indirect base in the researches; in international articles, concepts approach Swales' point of view, however, he is not cited directly as a reference. Thus, a discussion is developed relating the characteristics of the discursive community in relation to the notes found in the articles, theses and dissertations. Finally, it considers that the study of theories related to textual and discursive genres needs to be part of Terminology research, since the field of dictionaries and tools that represent specialized lexicons is a part of professional structures that share common goals and consensus, as well as specific forms of communication between peers (including specific genres and lexical), where the domain of relevant content and the discursive experience are factors of differentiation between the members themselves, being therefore the languages of specialty one of the characteristics of the discursive communities.

Keywords: Textual genres; Terminology; Discursive communities.

\section{Introdução}

Ao considerar as variedades de ciências e a consequente composição de universos de discursos próprios de cada área, observa-se que além de uma visão de mundo que é compartilhada por seus integrantes, há o desenvolvimento de uma linguagem para comunicação específica, que se utiliza de palavras do léxico geral para representar os conceitos e termos daquela comunidade. 0 entendimento e apreensão de uma dada ciência pressupõe o conhecimento da linguagem, da terminologia, com 0 intuito de dominar questões epistemológicas, métodos e técnicas, além de ser capaz de dominar as construções textuais próprias, como é ocaso dos gêneros acadêmicos. Assim, a consolidação da identidade das ciências perpassa a definição concisa de um 
universo conceitual e terminológico, estabelecendo também os gêneros textuais que serão utilizados para comunicação científica.

Desse modo, temos um cenário onde se verifica a convergência entre as questões das linguagens de especialidade e uma relação com o campo dos gêneros textuais e discursivos em duas perspectivas: no léxico especializado compartilhado pelos membros da comunidade discursiva, cujas características são bem discutidas por Swales (1990) e nos gêneros acadêmicos convencionados pela área.

Esse interesse de áreas diversas das Letras pela compreensão dos usos das teorias de gêneros se aproxima das considerações de Bhatia (2001), buscando entender modos de uso da língua em comunidades discursivas, e esse aspecto tem contribuído para sua popularidade no campo dos estudos do discurso e da comunicação, embora essa popularidade possa implicar variações.

Baseando-se no conceito de comunidade discursiva elaborado por Swales e aproximando-o dos estudos voltados à Terminologia e linguagens de especialidade, o objetivo deste trabalho é verificar a utilização do conceito de comunidade discursiva nas pesquisas em Terminologia. Para alcançar esse objetivo e delimitar um universo de investigação, foi realizada uma pesquisa em quatro bases de dados com cobertura nacional e internacional: Web of Science, Library \& Information Science Abstracts (LISA), Biblioteca Digital de Teses e Dissertações (BDTD) e Base de Dados Referenciais de Artigos de Periódicos em Ciência da Informação (BRAPCl).

Assim, o trabalho está organizado da seguinte forma: inicialmente, é apresentada uma contextualização acerca das teorias de gêneros textuais e discursivos trazendo, também, o conceito de comunidade discursiva; em seguida, desenvolve-se uma exposição sobre Terminologia, demonstrando como esta área se utiliza do conceito anteriormente discutido e, em um terceiro momento, é apresentada a análise dos resultados das pesquisas nas bases de dados e as constatações sobre as convergências entre os estudos de gêneros e os terminológicos, apresentando, em sequência, as considerações finais.

\section{Teoria de gêneros: definições e discussões}


As teorias de gêneros constituem uma temática que não é recente, porém continuam como pauta de discussões bastante atuais. Marcuschi (2008: 147) assinala que "O estudo de gêneros textuais não é novo e, no Ocidente, já tem pelo menos vinte e cinco séculos, se considerarmos que sua observação sistemática se iniciou em Platão. 0 que hoje se tem é uma visão nova do mesmo tema".

Por bastante tempo, o termo "gênero" se referiu à tradição literária, contudo, ganhou nova roupagem também se referindo às categorias de discurso oral ou escrito, relacionado ou não com a literatura. É importante destacar que há duas perspectivas de teorias de gênero, conforme ensina Rojo (2005): teorias de gênero de texto ou textuais e teoria de gêneros do discurso ou discursivos.

Enquanto a teoria voltada aos gêneros textuais dedica-se, sobretudo, à materialidade textual, a teoria de gêneros do discurso está ligada às questões bakhtinianas e são debatidos como objetos discursivos (ou enunciativos) e não ligados essencialmente à forma ou a tipologias, apresentando-se a partir de três dimensões: os temas, a forma composicional e a posição enunciativa do locutor, conforme os parâmetros da situação de produção. Cabe destacar que no presente trabalho a forma de referência temática escolhida foi o termo "gêneros textuais", uma vez que a fundamentação segue as teorias de Swales.

Motta-Roth (2008) evidencia que o conceito de gênero se estende para além dos limites da gramática e traz ao debate os textos que circulam na sociedade e a noção de aspectos sociocognitivos identificando a função social dos gêneros e as formas de controle social que são exercidas pelo discurso, que são baseadas nas considerações de Fairclough, fator que também aproxima as influências da análise sociológica da linguagem de Bakhtin.

A expressão das ideias através da linguagem resulta de uma série de possibilidades que podem variar desde a escolha do gênero apropriado, utilização de linguagem formal e técnica, resultando na organização de um texto que atenderá aos propósitos de uma determinada situação comunicativa. Contudo, é comum que a escolha do gênero e do repertório linguístico sigam estruturas tipificadas conforme o contexto em que os propósitos comunicativos 
serão realizados, que é o caso, por exemplo, das comunidades acadêmicas e profissionais.

Considerando que os propósitos comunicativos envolvem o autor do texto e também os leitores, Bazerman (2006: 22) destaca que

compreender os gêneros e seu funcionamento dentro dos sistemas e nas circunstâncias para as quais são desenhados pode ajudar você, como escritor, a satisfazer as necessidades da situação [de modo que] correspondam às expectativas dos outros.

Desse modo, pode-se depreender que geralmente existem alguns modelos textuais característicos e consolidados considerando formas comunicativas que estão em uso no quadro de uma determinada formação discursiva, requerendo certo grau de proficiência em linguagem.

Os gêneros estão presentes também na estrutura e organização das interações sociais, sendo considerados como formas culturais e cognitivas de ação social, corporificadas na linguagem, a partir da atividade social e intelectual da qual o texto faz parte. Assim, as ações individuais e sociais são realizadas por meio da linguagem, concretizadas em gêneros textuais e discursivos. Segundo Bazerman (2006), gêneros são tipos de enunciados conexos a situações retóricas e funcionam como molduras para a comunicação, sendo que esses frames são reconhecidos por outros sujeitos que compartilham do mesmo contexto.

Considerando que as teorias de gêneros estão nitidamente presentes nas características regulares dos tipos textuais e na posição dos sujeitos no contexto e que a motivação dessa série de situações são os propósitos comunicativos, é importante mencionar que Swales foi quem inicialmente observou e destacou essa característica:

Um gênero compreende uma classe de eventos comunicativos cujos exemplares compartilham os mesmos propósitos comunicativos. Esses propósitos são reconhecidos pelos membros mais experientes da comunidade discursiva original e constituem a razão do gênero. [...] 0 propósito comunicativo é o critério que é privilegiado e que faz com que o escopo do gênero se mantenha enfocado estreitamente em determinada ação retórica compatível com o gênero. Além do propósito, os exemplares do gênero demonstram padrões semelhantes, mas com variações em termos de estrutura, estilo, conteúdo e público-alvo. (SWALES 1990: 58) 
De acordo com o autor, são os propósitos comunicativos que conferem enfoque às ações retóricas e são identificáveis pelos membros de uma determinada comunidade. É intrínseca a necessidade de comunicação, assim como também é importante para o indivíduo enxergar-se membro de um grupo social. Para obter tal êxito, é preciso haver uma unidade entre os componentes desses contextos, incluindo a forma de comunicação, garantindo que se identifiquem mutuamente e, assim, a linguagem constitui-se em papel fundamental, especialmente na escrita, o que justifica a maior inclinação do presente trabalho às questões textuais.

Nesse sentido, Bazerman (1994) observou que as situações de comunicação apresentavam regularidades na forma e no conteúdo da comunicação, inclusive em situações nas quais esses modelos servem de base para o que não é familiar, ou seja, os conhecimentos prévios influenciam no aprendizado de outras tipologias genéricas.

Nesse caso, Devitt e Bastian (2015) postulam que é necessário o ensino da consciência de gêneros, ajudando a identificar quando se está recorrendo a novas estratégias ou a gêneros conhecidos, o que é útil em contextos profissionais e acadêmicos, onde frequentemente novas situações são vivenciadas junto à necessidade de se realizarem propósitos comunicativos através de gêneros diferentes. É ao que se refere Bhatia (2001) quando cita a imbricação de gêneros, em que profissionais experientes criam gêneros mais híbridos, aproximando-se do que Swales e Feak (2001) chamam de gêneros "intersticiais" tomando como exemplo as comunicações acadêmicas, em relação aos processos de escrita: pedidos, cartas de apresentação, currículos, cartas de recomendação, além de novos gêneros emergentes da comunicação científica, mas estritamente ligados à Internet, como weblogs acadêmicos (SWALES 2015).

Em situações acadêmicas e profissionais, ou seja, na comunicação científica o domínio dos gêneros típicos e da terminologia dos integrantes pode se tornar um indicativo nítido da hierarquia entre os membros: enquanto os aspirantes buscam compreender e se adaptar a essas formas e vocabulário, os membros proficientes detêm, inclusive, o poder de lançar novas formas genéricas e discutir, criar ou modificar conceitos. 
$\mathrm{Na}$ perspectiva de Swales, o propósito comunicativo do gênero é realizado por meio de moves (ou unidades retóricas), que conferem uma estrutura típica reconhecida entre os membros de uma comunidade discursiva, ou seja, existem determinados tipos textuais que servem a situações específicas, cuja convenção é intrínseca aos membros da comunidade.

Apesar disso, é natural deduzir que a existência de padrões comumente seguidos não implica em moldes e em estruturas invariavelmente predeterminadas, pois a inovação e a adaptação conforme os objetivos do propósito comunicativo podem variar em função da situação de comunicação.

Nesse sentido, é interessante trazer uma indagação de Bhatia levantada por Marcuschi (2008: 150): "Por que os membros de comunidades discursivas específicas usam a linguagem da maneira como o fazem?". Em seguida, tem-se o exemplo: por qual razão todos os que escrevem uma monografia de conclusão de curso fazem mais ou menos a mesma coisa em termos estruturais?

A resposta é complexa, mas observa-se que, além de questões socioculturais ou de moldes, existem ações comunicativas que se revestem de estratégias convencionais para alcançar determinados objetivos, seja alcançar uma boa nota para concluir um curso superior - no caso da monografia -, receber auxílio para uma viagem através de um ofício de solicitação etc. Dessa forma, um gênero, segundo Bhatia (1993: 13 apud CATUNDA 2004: 32):

É um evento comunicativo reconhecível, caracterizado por um conjunto de propósitos comunicativos identificados e, mutuamente entendidos pelos membros da comunidade profissional ou acadêmica na qual regularmente ocorre. Muitas vezes, ele é altamente estruturado e convencionalizado com restrições sobre as contribuições permissíveis em termos de sua intenção, posicionamento, forma e valor funcional. Essas restrições, contudo, são frequentemente exploradas pelos membros especialistas da comunidade discursiva, a fim de alcançar intenções particulares dentro da estrutura dos propósitos socialmente reconhecidos.

Pode-se observar que há uma ampliação de alguns aspectos da definição proposta por Swales, isso porque, para Bhatia, é o propósito comunicativo que caracteriza o gênero e qualquer modificação pode interferir, resultando em outro gênero. Assim,

A relevância da pesquisa de Bhatia, que retoma o conceito de gênero postulado por Swales, está exatamente no fato de este reforçar a importância da participação efetiva dos membros da 
comunidade discursiva no processo de cristalização dos gêneros (CATUNDA 2004: 32).

Assim, o conceito de comunidade discursiva, na visão de Swales, sugere que as convenções de discurso e das formas genéricas típicas são definidas por comunidades, uma vez que a forma de comunicação ocorra de modo específico dentro de cada comunidade, adaptando-se aos seus propósitos comunicativos e, dessa forma, os gêneros se constituem em esquemas cognitivos que não pertencem ao indivíduo, mas ao grupo (ou comunidade discursiva) direcionado aos escritores e leitores, distinguindo-se das comunidades de fala, que dirigem o foco para os falantes e ouvintes.

Swales propõe a identificação de uma comunidade discursiva a partir de seis características:

a) Possui um conjunto de metas comuns, apresentadas formalmente em documentos ou através de conhecimento tácito, havendo um alto grau de concordância entre os membros, sob pena de dissolução da comunidade discursiva;

b) Mecanismos de intercomunicação entre os membros, através de canais escritos como correspondência ou, até mesmo, de encontros e simples conversas;

c) Mecanismos participativos, principalmente, para o fornecimento de informações e feedback, melhorando o desempenho do que é produzido;

d) Apresenta um repertório de gêneros específicos, incluindo a seleção dos tópicos e dos elementos formais do discurso que são apropriados a eles;

e) Léxico especializado, ou seja, uma terminologia própria, termos técnicos que permitam a troca de comunicação eficiente entre os especialistas que formam a comunidade;

f) Possui membros antigos, com um grau adequado de conteúdo relevante e experiência discursiva, como também ocorre a inclusão de novos membros, que são apresentados a esse conhecimento pelos mais experientes.

Observa-se que uma comunidade discursiva atende à proposta inicial, que é a realização de propósitos comunicativos e que possui uma série de características que podem ser discutidas individualmente, dentre elas, a questão do léxico especializado, que é objeto de estudo de outras áreas, a exemplo da Terminologia, que será tratada na seção a seguir. 


\section{Temáticas de gênero em Terminologia: comunidades discursivas em foco}

A questão das comunidades discursivas muito tem contribuído, além dos gêneros discursivos; na literatura especializada em Terminologia, por exemplo, são frequentemente retratadas sem, no entanto, estarem enraizadas diretamente nos estudos de gêneros. Por outro lado, os autores que tratam dessa temática se apropriam das contribuições de Swales.

As ciências e as áreas de especialidades compõem universos de discurso que compartilham entre seus membros pontos de vista e vocabulário técnico, além de conceitos e métodos de comunicação, que são instrumentos de poder entre os membros experientes e condição necessária ao aprendizado para os que pretendem fazer parte da comunidade. Deste modo, a definição concisa de um universo conceitual e terminológico determina os fatos próprios de uma especialidade e, à medida que vai se constituindo, solidifica a ciência e a sua identidade epistemológica.

As linguagens de especialidade estão presentes no cotidiano da produção científica e o seu tratamento, tal qual o estabelecimento de novas unidades terminológicas, desempenham um papel fundamental. Nesse sentido, a Terminologia tem sido o instrumento essencial para a representação de informações, especialmente científicas, cuja utilidade está diretamente ligada à Organização do Conhecimento (enquanto dicionários léxicos e terminologias especializadas, a exemplo dos tesauros) no âmbito da Documentação, a fim de que os registros do conhecimento sejam organizados nos mais variados formatos (bibliotecas, bases de dados, repositórios científicos etc.), de modo que possam ser acessados posteriormente, além de contribuir para o mapeamento e organização conceitual das áreas do conhecimento, colaborando com a manutenção das ciências e entendimento entre os membros mais experientes e iniciantes. 
A International Organization for Standardization (ISO) define Terminologia como uma atividade relacionada com a sistematização e representação de conceitos, ou ainda como um conjunto de termos (conceitos) que constituem uma determinada área. Nesse sentido, Vogel (2007: 73) destaca que:

A terminologia preocupa-se com conceitos, definições de denominações, com a compilação, decisão, apresentação, criação e normalização de termos de campos especializados para fins de comunicação entre especialistas e profissionais. É uma disciplina que permite identificar, de forma sistemática, o vocabulário de uma determinada especialidade e analisá-lo.

Entretanto, Cabré (1995) assinala que não há uma definição fechada. Uma das principais causas da variedade de definições é a polissemia do termo terminologia, que designa, concomitantemente, uma disciplina, uma prática ou ainda o produto resultante dessa prática. A autora ressalta que, se abordada como teoria, a terminologia trata da relação entre conceitos e termos especializados; como prática (ou técnica), abarca um conjunto de métodos e atividades que se preocupam com a coleta, descrição, processamento e apresentação de termos, também conhecido por Terminografia; e, por último, como produto, configura-se em um conjunto de termos, ou ainda vocabulário voltado a uma determinada especialidade, recebendo, portanto, contribuições de diferentes ciências, a exemplo da Linguística, cujas ramificações advêm da lexicografia e lexicologia, da semântica, da sociolinguística e da linguística aplicada.

Dessa forma, de acordo com Carvalho (1992), a terminologia técnica faz parte do domínio da lexicografia, porém de uma lexicografia diferenciada "técnica", por assim dizer. 0 termo "dicionarizado" constitui uma unidade léxica que pode ser submetida a uma análise sintática e semântica no discurso onde é usada. Já o termo técnico é o suporte da noção que ele descreve e define e esse princípio acarreta consequências, por diferir da descrição do termo comum.

A descrição do léxico terminológico não visa ao estudo da língua em si: ele é, por definição, especializada num domínio delimitado, cujos termos não podem ser polissêmicos e remeterem a vários domínios, ou seja, são noções 
compartilhadas no âmbito de uma determinada comunidade, como popularmente nos referimos, por exemplo, aos jargões e termos técnicos.

A Terminologia realiza o controle da conceituação das palavras de um dado campo com o intuito de otimizar a comunicação/transferência de informações entre os membros de uma comunidade discursiva. Essa acepção é semelhante à de Lara (2004), que afirma que Terminologia pode ser considerada sob dois aspectos: terminologia teórica, que abarca metodologia, princípios que regem a compilação, a estruturação, o uso, a administração de conceitos; e terminologia metodológica, que seria um conjunto de termos relacionados a uma área de especialidade tendo, portanto, duplo aspecto: científico e lexicográfico.

Além do vocabulário, é sabido que os discursos orais e escritos provenientes de especialistas possuem normas discursivas próprias que se manifestam sob os vieses léxico, semântico, sintático, narrativo e discursivo. Desta maneira, os escritos e discursos orais possuem como objetivo a comunicação científica, onde uma das características é a utilização de vocabulário e gêneros textuais típicos.

Assim, chegando ao conhecimento de que as áreas de especialidade às quais as abordagens terminológicas se referem são equivalentes ao que Swales denomina de comunidades discursivas, esse conceito é presença constante nas investigações e aplicações. Entretanto, mencionando diretamente este autor, são relativamente poucos os trabalhos que o fazem.

Desse modo, as apreensões de gêneros têm ativamente contribuído para o desenvolvimento dos estudos que visam à compreensão da dinâmica que rege a evolução do universo conceitual e terminológico das ciências, tão importante para as comunidades discursivas que partilham das percepções particulares de cada área do conhecimento. Partindo desse pressuposto, foi realizada uma pesquisa para verificar a ocorrência do conceito de comunidade discursiva e sua influência em investigações de Terminologia. 


\section{Pesquisas em Terminologia e a influência direta do conceito de comunidade discursiva: resultados e considerações}

Uma vez que o conceito de comunidade discursiva acompanha a Terminologia e, conforme o objetivo geral do trabalho em averiguar a ocorrência do conceito de comunidade discursiva nas pesquisas terminológicas, realizou-se uma pesquisa em duas bases de dados internacionais: Library \& Information Science Abstracts (LISA) ${ }^{1}$ e Web of Science ${ }^{2}$; e em duas bases de dados nacionais: Biblioteca Digital Brasileira de Teses e Dissertações (BDTD) ${ }^{3}$ e Base de Dados Referenciais de Artigos de Periódicos em Ciência da Informação $(\mathrm{BRAPCl})^{4}$.

A escolha das bases se deu pelo fato de a Terminologia, apesar de estar no campo das ciências da linguagem, encontrar sua aplicação, principalmente, nas ciências voltadas à Documentação. Dessa forma, foram escolhidos repositórios que contemplassem essa observação e tivessem um universo de abrangência ampliado.

Em cada um dos repositórios foram avaliados os seguintes elementos dos textos recuperados: autor, título, resumo, palavras-chave, temáticas adjacentes e referências utilizadas. Essas informações foram tratadas e foi construído um quadro com a síntese das observações.

Nas bases de dados internacionais aqui trabalhadas, foram utilizados como termos de busca “discourse community" e "terminology", em língua

\footnotetext{
${ }^{1}$ Disponível em: <https://proquest.libguides.com/lisa $>$. Base de dados referencial na área de Ciência da Informação com cobertura internacional. Indexa mais de440 periódicos publicados em 68 países. 0 período disponível online é de 1969 até os dias atuais.

${ }^{2}$ Disponível em: <https://clarivate.com/products/web-of-science/>. Base de dados que tem cobertura multidisciplinar, abrangendo mais de 50.000 livros acadêmicos, 12.000 periódicos e 160.000 anais de congressos nas áreas de artes e humanidades, ciências sociais, dentre outras. ${ }^{3}$ Disponível em: <http://bdtd.ibict.br/vufind/>. A Biblioteca Digital Brasileira de Teses e Dissertações (BDTD) tem por objetivo integrar, em um único portal, os sistemas de informação de teses e dissertações existentes no país e disponibilizar para os usuários um catálogo nacional de teses e dissertações em texto integral, possibilitando uma forma única de busca e acesso a esses documentos.

${ }^{4}$ Disponível em: <https://www.brapci.inf.br/>. Base de dados de Periódicos em Ciência da Informação publicados no Brasil desde 1972.
} 
inglesa, uma vez que é o idioma oficial das referidas publicações. Na LISA, a realização da busca com os termos citados retornou trinta e quatro resultados, conforme a Figura 1:

Figura 1 - Resultados de busca na base de dados LISA

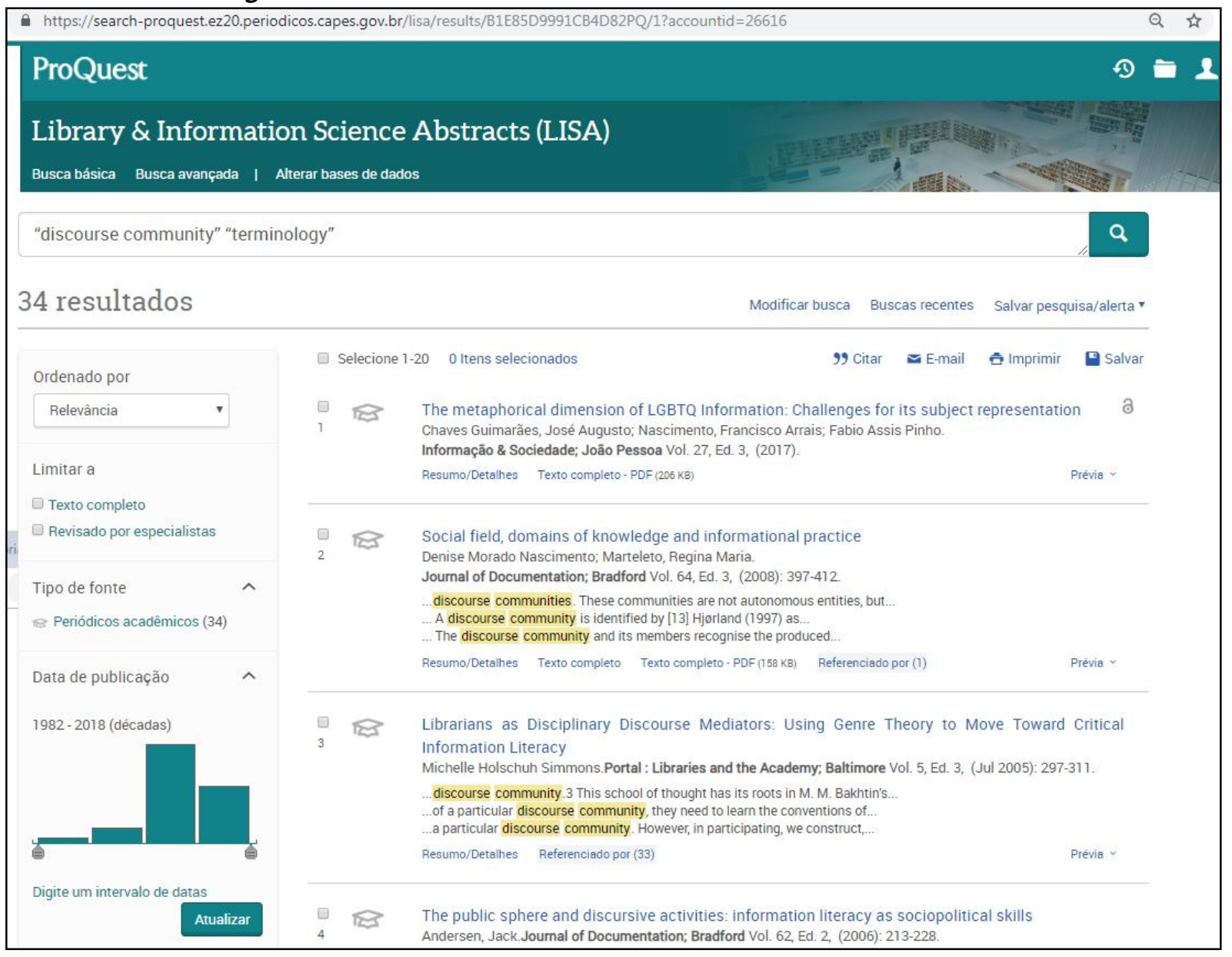

Fonte: os autores, através de captura de tela

Cada trabalho recuperado foi analisado individualmente em texto integral, em que o exame minucioso revelou que apenas nove resultados tratavam, ao mesmo tempo, dos temas terminologia e comunidade discursiva. Os demais trabalhos, apesar de alguns se referirem a comunidades discursivas, não o faziam de modo aprofundado, apenas fazendo alguma citação ou usando o conceito de forma genérica. Outros temas encontrados nos textos com certa frequência foram os seguintes: comunidades de aprendizado; línguas para fins específicos; inglês para fins específicos; análise de domínio (conceito aplicado na área de Ciência da Informação, na qual está contida a Documentação que utiliza a definição de comunidades discursivas proposta de Swales como base); 
análise de discurso, information literacy; gêneros textuais e acadêmicos. Dessa maneira, foram considerados os resultados que de fato estavam alinhados às duas temáticas, destacando os temas adjacentes, sintetizados no Quadro 1:

Quadro 1 - Síntese das informações dos artigos recuperados na LISA

\begin{tabular}{|c|c|c|}
\hline Título & $\begin{array}{l}\text { Autor(es)/Ano de } \\
\text { publicação }\end{array}$ & Conteúdo identificado \\
\hline $\begin{array}{l}\text { 'It's the journey and the } \\
\text { destination': shape and } \\
\text { the emergent property } \\
\text { of genre in evaluating } \\
\text { digital documents }\end{array}$ & $\begin{array}{l}\text { DILLON, A.; VAUGHAN, } \\
\text { M. (1997) }\end{array}$ & $\begin{array}{l}\text { Hipermídia; Pesquisas; } \\
\text { Terminologia; } \\
\text { Navegação; } \\
\text { Comunidades } \\
\text { discursivas; } \\
\text { Recursos de Informação. }\end{array}$ \\
\hline $\begin{array}{l}\text { Establishment } \\
\text { glossaries: their basic } \\
\text { functions }\end{array}$ & RIGGS, F. W. (1982) & $\begin{array}{l}\text { Construção } \\
\text { glossários; } \\
\text { Materiais publicados; } \\
\text { Terminologia; Conceitos } \\
\text { dos termos; } \\
\text { Comunidades } \\
\text { discursivas; } \\
\text { Conhecimento } \\
\text { especializado. }\end{array}$ \\
\hline $\begin{array}{l}\text { Discourse community of } \\
\text { professionals }\end{array}$ & $\begin{array}{l}\text { KRHUTOVÁ, Milena } \\
\text { (2012) }\end{array}$ & $\begin{array}{l}\text { Comunidade de } \\
\text { profissionais; } \\
\text { Comunidades } \\
\text { discursivas; Língua } \\
\text { inglesa para fins } \\
\text { específicos; } \\
\text { Terminologia. }\end{array}$ \\
\hline $\begin{array}{l}\text { Gender Sensitivity in } \\
\text { Specialized } \\
\text { Communication: A } \\
\text { preliminary corpus- } \\
\text { based study of the LSP } \\
\text { in Economics }\end{array}$ & BOWKER, Lynne (2001) & $\begin{array}{l}\text { Gêneros; Terminologia; } \\
\text { Línguas para fins } \\
\text { específicos. }\end{array}$ \\
\hline $\begin{array}{l}\text { Approaching the } \\
\text { Concept of Discourse } \\
\text { Community }\end{array}$ & SWALES, John (1987) & $\begin{array}{l}\text { Gêneros; Comunidades } \\
\text { discursivas; } \\
\text { terminologia. }\end{array}$ \\
\hline $\begin{array}{l}\text { Social field, domains of } \\
\text { knowledge and } \\
\text { informational practice }\end{array}$ & $\begin{array}{l}\text { NASCIMENTO, Denise } \\
\text { Morado; MARTELETO, } \\
\text { Regina Maria (2004) }\end{array}$ & $\begin{array}{l}\text { Informação Construída; } \\
\text { Sociologia da Cultura; } \\
\text { Comunidades } \\
\text { Discursivas. }\end{array}$ \\
\hline $\begin{array}{l}\text { Domain analysis in } \\
\text { information science: } \\
\text { Eleven approaches - } \\
\text { traditional as well as } \\
\text { innovative }\end{array}$ & $\begin{array}{l}\text { HJORLAND, Birger } \\
(2002)\end{array}$ & $\begin{array}{l}\text { Análise de domínio; } \\
\text { Documentação; } \\
\text { Terminologia; } \\
\text { Comunidades } \\
\text { discursivas }\end{array}$ \\
\hline
\end{tabular}




\begin{tabular}{|l|l|l|}
\hline $\begin{array}{l}\text { Semiotics and indexing: } \\
\begin{array}{l}\text { An analysis of the } \\
\text { subject indexing } \\
\text { process }\end{array}\end{array}$ & MAI, Jens-Erik (2001) & $\begin{array}{l}\text { Documentação; } \\
\text { Indexação; Análise de } \\
\text { domínio; Comunidades } \\
\text { discursivas; } \\
\text { Terminologia. }\end{array}$ \\
\hline $\begin{array}{l}\text { A framework for work } \\
\text { task based thesaurus } \\
\text { design }\end{array}$ & $\begin{array}{l}\text { NIELSEN, Marianne } \\
\text { Lykke (2001) }\end{array}$ & $\begin{array}{l}\text { Tesauros; Análise de } \\
\text { domínio; Comunidades } \\
\text { discursivas; } \\
\text { Terminologia. }\end{array}$ \\
\hline
\end{tabular}

Fonte: os autores

No Quadro 1 é possível observar que coexistem diversas temáticas juntamente com as questões das comunidades discursivas e terminologias, como a construção de ferramentas terminológicas (como os glossários e os tesauros), geralmente voltados às práticas documentais, assim como o comportamento de busca de informação. As questões levantadas pelos artigos estão alinhadas com a área temática predominante da base de dados LISA: Ciência da Informação, Biblioteconomia e, conseguintemente, Documentação.

Em seguida, na base de dados Web of Science, os termos utilizados para a pesquisa foram os mesmos que na base anterior: "discourse community" e "terminology". 
Figura 2 - Resultados de busca na base Web of Science

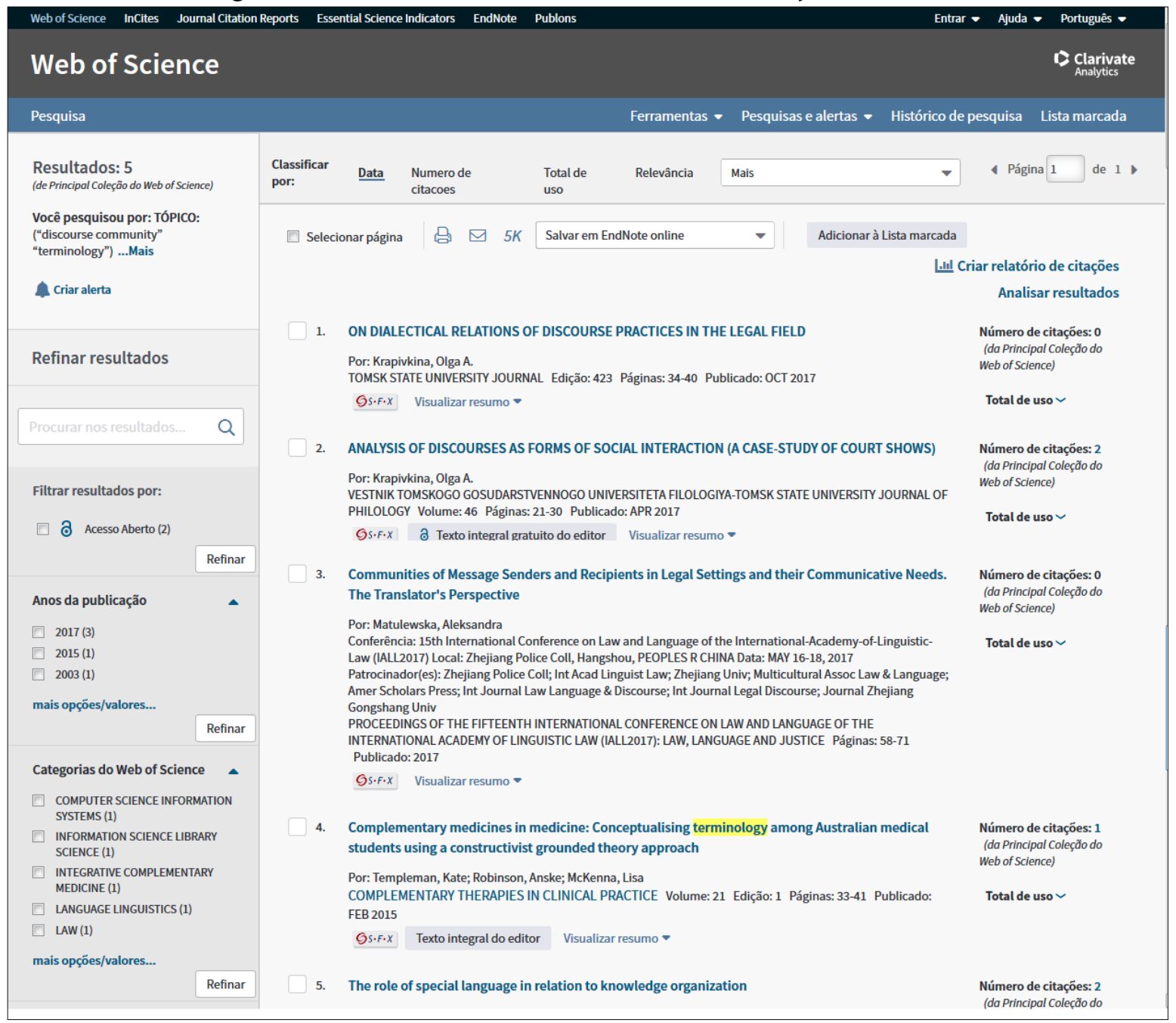

Fonte: captura de tela

Retornaram cinco resultados a partir do argumento de busca, sintetizados no quadro abaixo, cuja primeira característica a observar é o ano de publicação recente da maioria dos trabalhos:

Quadro 2 - Síntese das informações dos artigos recuperados na Web of Science

\begin{tabular}{|c|c|c|}
\hline Título & $\begin{array}{l}\text { Autor(es)/Ano de } \\
\text { publicação }\end{array}$ & Conteúdo identificado \\
\hline $\begin{array}{l}\text { Complementary } \\
\text { medicines in medicine: } \\
\text { Conceptualizing } \\
\text { terminology among } \\
\text { Australian medical } \\
\text { students using a } \\
\text { constructivist grounded } \\
\text { theory approach }\end{array}$ & $\begin{array}{l}\text { TEMPLEMAN, Kate; } \\
\text { ROBINSON, Anske; } \\
\text { MCKENNA, Lisa. } \\
(2015)\end{array}$ & $\begin{array}{l}\text { Medicina integrativa; } \\
\text { Medicina complementar; } \\
\text { Medicina alternativa; } \\
\text { Terminologia médica e } \\
\text { comunidade discursiva } \\
\text { médica; Educação } \\
\text { médica. }\end{array}$ \\
\hline
\end{tabular}




\begin{tabular}{|l|l|l|}
\hline $\begin{array}{l}\text { The role of special } \\
\text { language in relation to } \\
\text { knowledge organization }\end{array}$ & $\begin{array}{l}\text { THELLEFSEN, M. } \\
(2003)\end{array}$ & $\begin{array}{l}\text { Terminologia; Linguagem } \\
\text { de especialidade; Ciência } \\
\text { da Informação; } \\
\text { Cibersemiótica; Análise de } \\
\text { domínio. }\end{array}$ \\
\hline
\end{tabular}

Fonte: os autores

A análise dos artigos revela uma forte relação entre as temáticas investigadas. Inclusive, a noção de comunidades discursivas, conforme a proposta de Swales, é questão central em ambos os textos. Porém, o autor novamente não foi utilizado como base: na primeira ocorrência, a obra base é de J. Flatt, que versa sobre a análise crítica do discurso relacionada à medicina complementar; na segunda, o texto se sustenta nas acepções de Birger Hjørland, um autor de grande destaque na área de Ciência da Informação, que, entretanto, declara em suas obras que o conceito de comunidade discursiva ao qual se refere é justamente o de Swales que, portanto, é indiretamente utilizado.

No caso das bases de dados nacionais, mais uma vez os termos selecionados para compor a busca foram "comunidade discursiva" e "terminologia", desta vez em língua portuguesa e, na BDTD, obteve-se o seguinte resultado: 
Figura 3 - Resultados de busca na BDTD



Fonte: captura de tela

A análise dos resultados permitiu identificar uma tese e uma dissertação pertencentes a áreas diferentes: uma em Linguística e outra em Ciência da Informação e, em relação às temáticas, o seguinte panorama é obtido:

Quadro 3 - Síntese das informações dos artigos recuperados na BDTD

\begin{tabular}{|c|c|c|}
\hline Título & $\begin{array}{l}\text { Autor(es)/Ano de } \\
\text { publicação }\end{array}$ & Conteúdo identificado \\
\hline $\begin{array}{l}\text { Textos forenses: um } \\
\text { estudo de seus gêneros } \\
\text { textuais e sua relevância } \\
\text { para o gênero sentença }\end{array}$ & $\begin{array}{l}\text { PIMENTA, Viviane } \\
\text { Raposo (2007) }\end{array}$ & $\begin{array}{lr}\text { Gêneros textuais; Tipologia } \\
\text { textual; } & \text { Linguística } \\
\text { Textual; } & \text { Filosofia da da } \\
\text { Linguagem; } & \text { Direito } \\
\text { Processual } & \text { Penal; }\end{array}$ \\
\hline
\end{tabular}




\begin{tabular}{|l|l|l|}
\hline & & $\begin{array}{l}\text { Comunidades discursivas; } \\
\text { Terminologia especializada. }\end{array}$ \\
\hline $\begin{array}{l}\text { Análise de domínio para } \\
\text { avaliação de tesauros: } \\
\text { uma experiência com a } \\
\text { cadeia produtiva do do } \\
\text { calçado no Brasil }\end{array}$ & $\begin{array}{l}\text { Leraunilena Josimari } \\
(2011)\end{array}$ & $\begin{array}{l}\text { Tesauros; Indústria de } \\
\text { calçados no Brasil; } \\
\text { Linguagens de indexação; } \\
\text { Análise de domínio. }\end{array}$ \\
\hline
\end{tabular}

Fonte: os autores.

As pesquisas, apesar de estarem vinculadas a programas de pósgraduação diferentes, compartilham dos mesmos princípios: o estudo de comunidades discursivas e a reflexão a respeito da importância e do estabelecimento de uma terminologia para os respectivos contextos. Ambas tratam amplamente do conceito de comunidades discursivas de Swales, relacionando-o às características das linguagens dos grupos para que diretrizes voltadas para a construção de instrumentos de controle terminológico pudessem ser estabelecidas. A diferenciação das duas pesquisas está no caso da tese de Lorenzon, que também utilizou o conceito de análise de domínio proposto por Birger Hjørland, que já tivera ocorrência em um dos itens recuperados da Web of Science e que, conforme já tratado, baseia-se em Swales para estabelecer o termo. A temática de análise de domínio tem alcançado evidência em Ciência da Informação $(\mathrm{Cl})$ e, dessa forma, influencia mais uma abertura para a pesquisa de gêneros, com a ênfase em comunidades discursivas.

$\mathrm{Na}$ verificação da base de dados $\mathrm{BRAPCl}$, especializada em $\mathrm{Cl}$, onde Terminologia é uma das abordagens tradicionais da área, o termo de busca foi somente "comunidades discursivas", alcançando, pois, os seguintes resultados: 
Figura 4 - Resultados de busca na BRAPCI

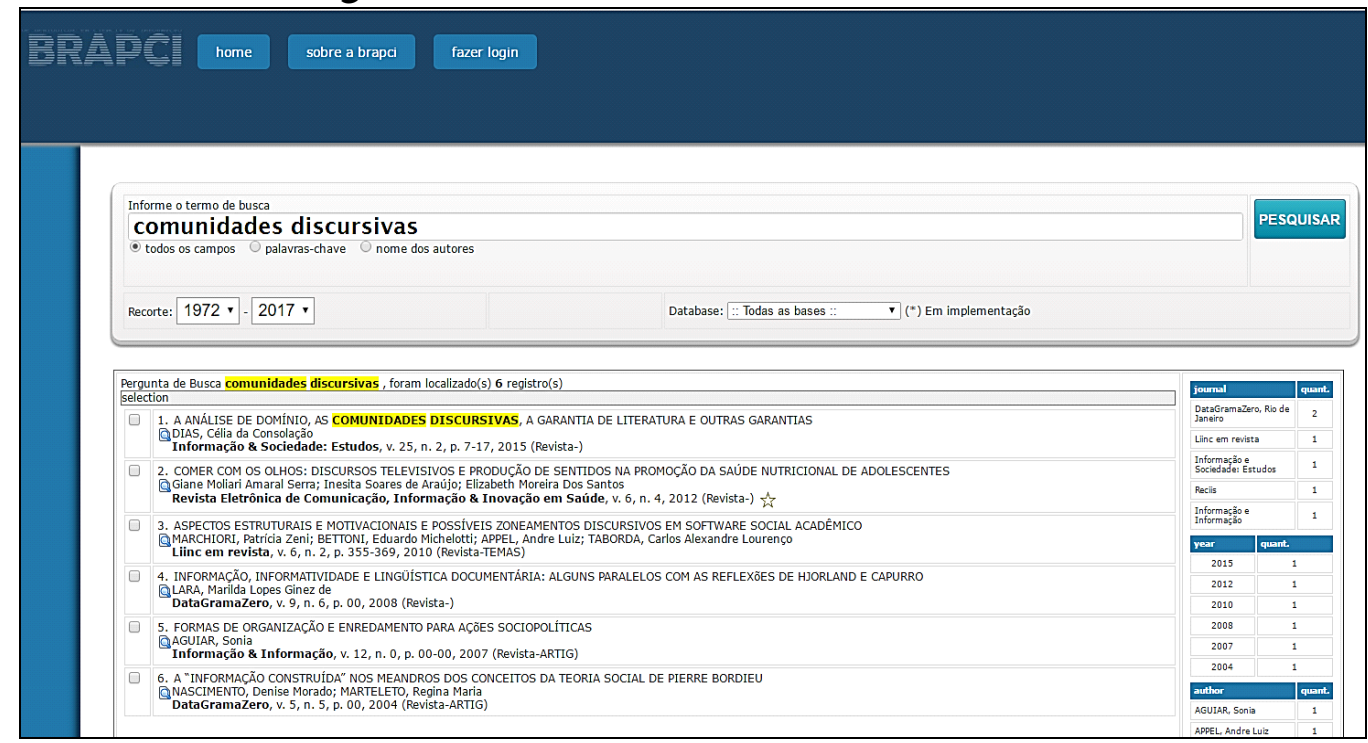

Fonte: captura de tela

Foram recuperados seis artigos científicos, analisados individualmente, onde se observou que, de fato, todos tratavam de comunidades discursivas, porém, quatro desses trabalhos se encaixavam nos objetivos aqui definidos, excetuando-se os demais. Obteve-se, então, o seguinte cenário:

Quadro 4 - Síntese das informações dos artigos recuperados na BRAPCI

\begin{tabular}{|c|c|c|}
\hline Título & $\begin{array}{l}\text { Autor(es)/Ano de } \\
\text { publicação }\end{array}$ & Conteúdo identificado \\
\hline $\begin{array}{l}\text { A análise de domínio, as } \\
\text { comunidades discursivas, } \\
\text { a garantia de literatura e } \\
\text { outras garantias }\end{array}$ & $\begin{array}{l}\text { DIAS, Célia da } \\
\text { Consolação (2015) }\end{array}$ & 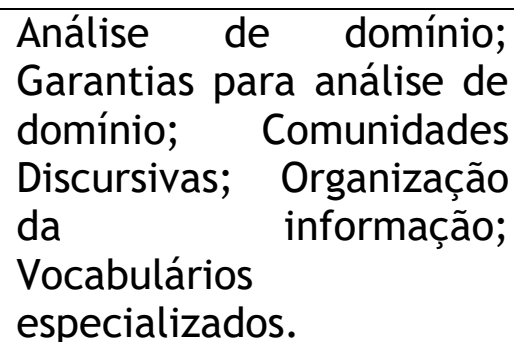 \\
\hline $\begin{array}{l}\text { Aspectos estruturais e } \\
\text { motivacionais e possíveis } \\
\text { zoneamentos discursivos } \\
\text { em software social } \\
\text { acadêmico }\end{array}$ & $\begin{array}{l}\text { MARCHIORI, } \\
\text { Patrícia Zeni; } \\
\text { BETTONI, Eduardo } \\
\text { Michelotti; APPEL, } \\
\text { Andre Luiz; } \\
\text { TABORDA, Carlos } \\
\text { Alexandre } \\
\text { Lourenço (2010) }\end{array}$ & $\begin{array}{llr}\text { Sistemas de } & \text { social } \\
\text { bookmarking; Sistemas de } \\
\text { gerenciamento } \\
\text { referências; } & \text { Marcação de } \\
\text { recursos na web; } & \text { na } \\
\text { Infometria; } & & \text { Software } \\
\text { social e } & \text { comunidades } \\
\text { discursivas. } & \end{array}$ \\
\hline $\begin{array}{l}\text { Informação, } \\
\text { informatividade } \\
\text { linguística documentária: } \\
\text { alguns paralelos com as } \\
\text { reflexões de Hjorland e } \\
\text { Capurro }\end{array}$ & $\begin{array}{l}\text { LARA, } \quad \text { Marilda } \\
\text { Lopes Ginez de } \\
(2008)\end{array}$ & $\begin{array}{l}\text { Linguística documentária; } \\
\text { Informação } \\
\text { informatividade; } \\
\text { Informação } \\
\text { comunidades } \\
\text { Discursivas; Mensagem }\end{array}$ \\
\hline
\end{tabular}




\begin{tabular}{|c|c|c|}
\hline & & $\begin{array}{l}\text { Documentária; Linguagens } \\
\text { especializadas. }\end{array}$ \\
\hline $\begin{array}{l}\text { A “informação construída" } \\
\text { nos meandros dos } \\
\text { conceitos da teoria social } \\
\text { de Pierre Bordieu }\end{array}$ & $\begin{array}{l}\text { NASCIMENTO, } \\
\text { Denise Morado; } \\
\text { MARTELETO, } \\
\text { Regina Maria } \\
\text { (2004) }\end{array}$ & $\begin{array}{l}\text { Informação Construída; } \\
\text { Sociologia da Cultura; } \\
\text { Comunidades Discursivas. }\end{array}$ \\
\hline
\end{tabular}

Fonte: os autores.

Os quatro artigos têm em comum a base nos pressupostos de Swales, que é diretamente citado em três desses. Acessando os textos completos, foi possível notar que as "comunidades discursivas" em $\mathrm{Cl}$ estão estreitamente relacionadas a dois aspectos da área: terminologia e análise de domínio, esta última alicerçada em Hjørland (1997) e, segundo este, o modo como a organização do conhecimento se estrutura, os modelos de cooperação, as variáveis da linguagem e comunicação, a literatura e a sua distribuição, bem como os critérios de relevância, são alguns dos elementos de trabalho destas comunidades, assim como seus papéis na sociedade. Por sua vez, esse conceito tem como ponto de partida os pressupostos de Swales sobre comunidades discursivas.

Relacionando esse conceito com Terminologia, tem-se uma conjunção onde indivíduos partilham, desde o entendimento conceitual dos termos técnicos, estilos de escrita (expectativas de discurso), incluindo os gêneros que são comuns em cada comunidade. Além do mais,

no âmbito da Linguística Documentária, as comunidades discursivas constituem o principal apoio para a integração das referências de uso aos instrumentos de organização e acesso à informação. A operacionalização desse procedimento é passível via diálogo com a Terminologia que, enquanto campo de estudos da Linguística Aplicada, sugere formas que permitem identificar, compreender e integrar a terminologia concreta efetivamente utilizada pelas comunidades discursivas (LARA 2008: 4).

Temos, portanto, uma convergência documentada entre as investigações de gênero e Terminologia, inclusive, com o reconhecimento de autores que tratam de ambos, concomitantemente. De modo geral, pode-se ratificar a evidente importância das teorias de gêneros textuais em contextos acadêmicos e profissionais, considerando as terminologias próprias e as características peculiares de cada ramo do conhecimento, no que concernem a seus objetivos 
comuns, as formas de comunicação, os padrões textuais, a massa crítica, dentre outros pontos.

Os resultados também revelaram que, embora amplamente utilizado nos estudos terminológicos, faltam maior aprofundamento e novas investigações que compreendam o conceito de comunidades discursivas e sua aplicação, para que sejam mais bem embasados, uma vez que as linguagens de especialidade, de fato, compõem uma das características dessas comunidades discutidas por Swales e que, portanto, devem se fazer presentes em trabalhos futuros.

\section{Considerações finais}

Haja vista a discussão realizada neste artigo constatou-se que as abordagens e teorias de gênero se localizam além do clássico, enquadrando estruturas com características pré-definidas ou direcionadas à gramática, estando voltadas para o uso social da língua e da comunicação, de acordo com as circunstâncias do contexto, sendo também, definidas em possibilidades de escolha para atender aos propósitos comunicativos, em que se desdobram estruturas tipificadas e repertório discursivo comum aos que compartilham do mesmo contexto, a exemplo da comunicação acadêmico-científica entre especialistas.

Ao longo do presente texto, foram tratadas as questões relacionadas às teorias de gênero, o conceito de comunidades discursivas elaborado por Swales e a sua influência nos estudos em Terminologia, desenvolvendo uma pesquisa sobre as duas temáticas em bases de dados, buscando convergências e tecendo, assim, as respectivas considerações.

Este estudo permitiu observar que os gêneros são requisitos fundamentais para que se compreenda o funcionamento social da língua através da expressão textual, tanto para a escolha da melhor composição como também para ajustar-se aos modos de comunicação do grupo (ou grupos) ao qual estamos vinculados (ou àqueles a que aspiramos), permitindo uma reflexão sobre o comportamento retórico, ou seja, a comunidade discursiva é fator 
determinante para a comunicação. Outrossim, temos margem para os estudos de linguagens de especialidade, onde se desenvolve a Terminologia enquanto léxico de uma área e como ciência que envolve as ferramentas de controle de vocabulário.

Nesse sentido, observou-se também que, embora grande parte das publicações bibliográficas remeta ou seja embasada nos princípios das comunidades discursivas postulados por Swales, é necessário que exista maior enfoque e reflexão sobre o tema, mesmo que esse conceito esteja implícito nas aplicações terminológicas, a fim de que os trabalhos em Terminologia sejam melhor fundamentados, o que pode refletir sensivelmente nos resultados de pesquisa, nas ferramentas desenvolvidas que melhor revelariam os propósitos da área representada e, finalmente, no aperfeiçoamento mais sólido dessa ciência.

\section{Referências}

Bazerman, C. Gênero, agência e escrita. São Paulo: Cortez, 2006.

. Gêneros textuais, tipificação e interação.2. ed. São Paulo: Cortez, 2006.

. Systems of genre and the enactment of social intentions. In: Freedman \& Medway. Rethinking genre. London: Taylor \&Francis, 1994. p. 79-101.

BHATHIA, V. K. Análise de gêneros hoje. Revista de Letras, Fortaleza, n. 23, v. 1/2, jan/dez. 2001. p. 102-115. Trad. Benedito G. Bezerra.

BIASI-RodrIGUeS, B.; BezerRA, B. G. Propósito comunicativo em análise de gêneros. Linguagem em (Dis)curso, Tubarão - SC, v. 12, n. 1, p. 231-249, 2012. Disponível em: http://www.scielo.br/pdf/ld/v12n1/v12n1a11. Acesso em: 18 fev. 2019.

CABRÉ, M. T. La terminologia hoy: concepciones, tendencias y aplicaciones. Ciência da Informação, Brasília, DF, v. 24, n. 3, 1995. Disponível em: http://revista.ibict.br/ciinf/article/view/567. Acesso em: 22 fev. 2019.

Carvalho, N. M. A terminologia técnico-científica: aspectos linguísticos e metodológicos. Recife: EdUFPE, 1992. 
CATUNDA, E. L. Um Estudo do Gênero Jurídico Acórdão. 2004. 121 f. Dissertação (Mestrado em Linguística) - Departamento de Letras Vernáculas, Universidade Federal do Ceará, 2004.

DeVITT, A.; Bastian, H. Algumas ideias para ensinar novos gêneros a partir de velhos gêneros. In: Dionísıo, A. P.; CaValcantI, L. P. (Org.). Gêneros na linguística e na literatura: Charles Bazerman: 10 anos de incentivo à pesquisa no Brasil. Recife: Ed. Universitária da UFPE/Pipa Comunicação, 2015. p. 97-121.

HJøRLAND, B. Information seeking and subject representation: an activitytheoretical approach to Information Science. New York: Greenwood Press, 1997.

LARA, M. L. G. Informação, informatividade e linguística documentária: alguns paralelos com as reflexões de Hjorland e Capurro. DataGramaZero, João Pessoa, v. 9, n. 6, p. 00, 2008. Disponível em: http://basessibi.c3sl.ufpr.br/brapci/v/7544. Acesso em: 08 jan. 2019.

, M. L. G. Linguagem documentária e terminologia. Transinformação, Campinas, n. 16, p. 232-240, set./dez. 2004. Disponível em: http://www.scielo.br/pdf/tinf/v16n3/03.pdf. Acesso em: 24 fev. 2019.

MARCUSCHI, L. A. Produção textual, análise de gêneros e compreensão. São Paulo: Parábola Editorial, 2008.

MiLleR, C. R. Genre as social action. Quarterly Journal of Speech, v. 70,1984, 151-167. Disponível em: http://www4.ncsu.edu/ crmiller/Publications/MillerQJS84.pdf

MotTA-Roth, D. Análise crítica de gêneros: contribuições para o ensino e a pesquisa de linguagem. D.E.L.T.A. [online]. São Paulo, v. 24, n. 2, p. 341-383, $2008 . \quad$ Disponível em: http://www.scielo.br/pdf/delta/v24n2/v24n2a07.pdf Acesso em 12 dez. 2018.

Rojo, R. Gêneros do discurso e gêneros textuais: questões teóricas e aplicadas. In: MeURer, J. L.; BoninI, A.; MOTTA-Roth, D. Gêneros: teorias, métodos, debates. São Paulo: Parábola, 2005. p.184-207.

SWALES, J. The Concept of Discourse Community. In: - Genre analysis: English in academic and research settings. Cambridge: Cambridge University Press, 1990. p. 21-32. Disponível em: https://moodle.csun.edu/pluginfile.php/3333572/mod_resource/conte nt/2/swales_concept-of-discourse-community.pdf. Acesso em: 07 jul. 2018.

. The semiperiphery of academic writing: discourses, communities and practices (Book Review). English for Specific Purposes, V. 39, July 2015, p. 80-82. Disponível em: 
http://www.sciencedirect.com/science/journal/08894906/39/supp/C. Acesso em: 09 jul. 2018.

Swales, J.; Feak, C. B. Academic Communications and the Graduate Student. Pedagogy, v.1, n. 1, p. 176-178, 2001.

Vogel, M. J. M. A noção de estrutura linguística e de processo de estruturação $e$ sua influência no conceito e na elaboração de linguagem documentária. 2007. 124 f. Dissertação (Mestrado em Ciência da Informação) - Escola de Comunicação e Artes, Universidade de São Paulo, 2007.

Recebido em: 26/04/2019

Aceito em: 12/09/2019

Publicado em novembro de 2019 